\title{
Virtual Simulation of New Residential Buildings in Lingnan Using Vernacular Wisdom
}

\author{
Bin $\mathrm{Li}^{1}$, Weihong Guo ${ }^{2}$, Marc Aurel Schnabel ${ }^{3}$, Ziqi Zhang ${ }^{4}$ \\ ${ }^{1,2}$ South China University of Technology ${ }^{3}$ Victoria University of Wellington ${ }^{4}$ South \\ China University Of Technology \\ 1,4\{445453185|393336093\}@qq.com²whguo@scut.edu.cn³MarcAurel.Schnabel@vuw. \\ ac.nz
}

\begin{abstract}
Every new idea has some sort of precedent or echoes from the past. It is the same for the new residential buildings in Lingnan, China. In Lingnan, the vernacular knowledge of building design has been established over thousands of years. Whether it is suitable for use today should be verified. In this research, virtual simulations are employed to arrive at an overall conclusion. Virtual simulations based on PHOENICS, ENVI MET, CadnaA, and Ecotect software were separately used for analysing the case of new residential buildings located in Lingnan. The study analysed the wind, thermal, acoustic, and light environments, which are four aspects of these new residential buildings. According to the results of our research, the paper discussed ways to amend and improve the new residential buildings that sit within the overall spirit of the vernacular knowledge of Lingnan; thus, it helps to put the traditional knowledge into the current context. The vernacular knowledge from XS to XL scale contexts, such as Feng-shui, was verified as being suitable for use in Lingnan today.
\end{abstract}

Keywords: Virtual simulation, Vernacular wisdom, residential building, Lingnan, Feng-shui

\section{INTRODUCTION \\ PROBLEMS}

China is undergoing rapid urbanisation (Liu et al., 2018). In Lingnan, a part of the south region of China, countless new residential buildings have emerged through fast development in recent years. However, whether the local vernacular knowledge for architectural design is still suitable for new residential buildings has not been explored. The paper analyses its validity.

\section{BACKGROUND}

Vernacular knowledge for architectural design existed in China for thousands of years (Li et al., 2020). The considerations for forming the best-integrated effect include wind, thermal, acoustic, light environment and other parameters. In Lingnan, a unique vernacular knowledge exists that is based on different environmental conditions (Ji et al., 2018). 


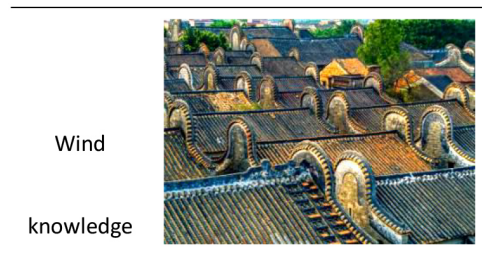

A: Comb layout

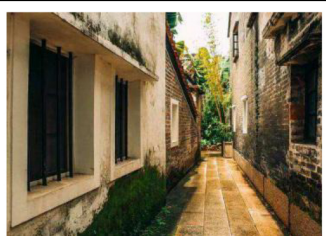

B: Cold lanes

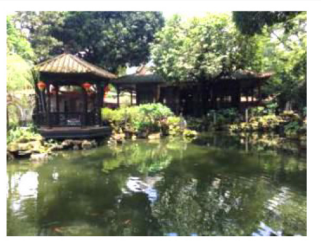

E: Water areas
Table 1

Vernacular wisdom in Lingnan.

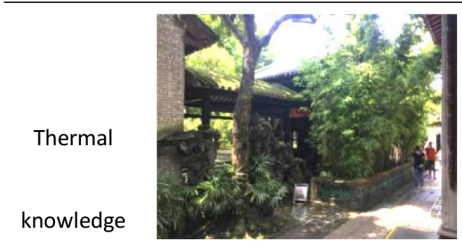

D: Greenery

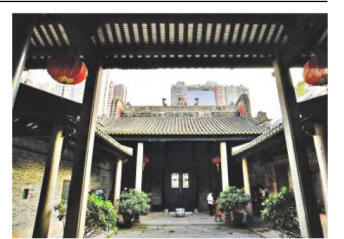

C: Courtyard

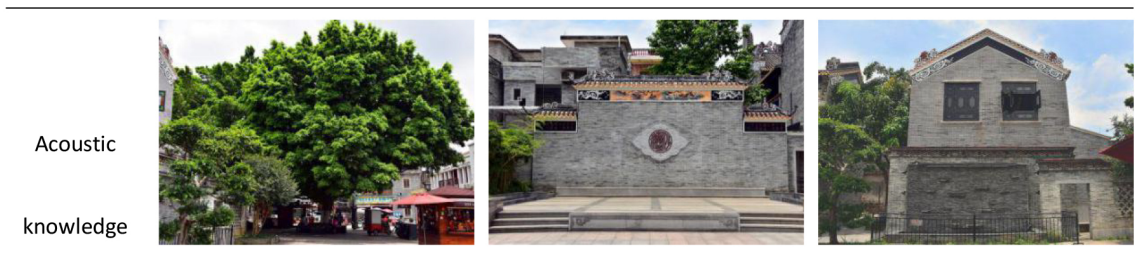

G: High-rise plants

$H$ : Soundproof walls

I: Tight building envelopes

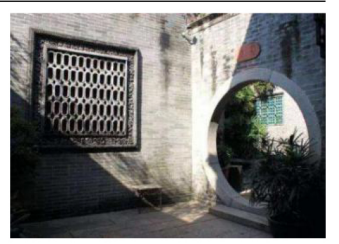

F: Hollow fences

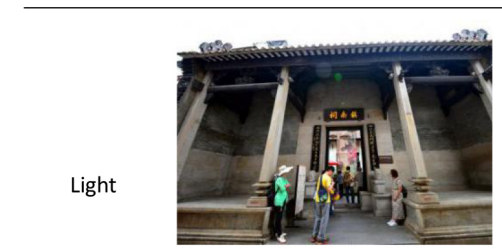

knowledge

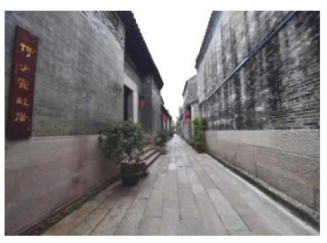

K: Sun-proof layout

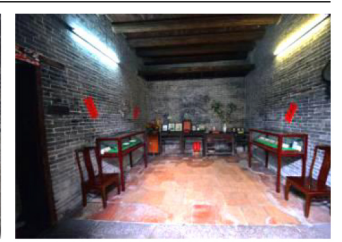

L: reduced ground reflection

material 
Table 2

Virtual simulation software.

\section{VERNACULAR WISDOM IN LINGNAN}

Regarding the wind environment, most of the area in Lingnan has prevailing northeast and east winds from October to March and southeast and southwest winds from April to September. The annual average wind speed is 1-4m/s (MOHURD, 1993). Because the poor ventilation will cause sultry indoor air and humidity problems, the layout of buildings generally considers the wind direction. Block layout is better to detach them from each other, which is called 'comb layout' by locals (Table 1-A). Ventilation alleys are formed between the single buildings, which are called 'cold lanes' in Lingnan (Table 1-B). The courtyard is also necessary for local residential buildings to achieve a better wind environment (Table 1-C) (Zeng et al., 2017).

As for the thermal environment, it is hot in Lingnan. The average temperature in January is higher than $10^{\circ} \mathrm{C}$; the average temperature in July is $25-29^{\circ} \mathrm{C}$. Furthermore, the number of days with an average daily temperature higher than or equal to $25^{\circ} \mathrm{C}$ is between 100 and 200 days (MOHURD, 1993). Considering the problems of high indoor temperatures, measures to increase greenery (Table 1-D), water areas (Table 1-E), and hollow fences (Table 1-F) were typically adopted to ensure comfort in Lingnan (Gao \& Cheng, 2011).

The acoustic environment is mainly related to the space-time state of the sound source and the soundproofing performance of building materials. Vernacular knowledge suggests the adoption of high-rise plants (Table 1-G), soundproof walls (Table $1-\mathrm{H})$, and measures to enhance the tightness of the building envelope (Table 1-I) (Yang \& Zhou, 2015).

Regarding the light environment, Lingnan has a high solar elevation angle and intense solar radiation. For this reason, Western-facing exposure of façades or windows should be avoided. Additionally, vernacular knowledge proposes incorporating measures such as the inclusion of a sunshade roof (Table $1-\mathrm{J}$ ) and sun-proof layout (Table 1-K), as well as reduced use of reduced ground reflection material ( $\mathrm{Ta}$ ble 1-L) (Lin et al., 2019).

\section{MOTIVATION}

The vernacular architectural and building knowledge in Lingnan considers building-scales from XS (room) to XL (neighbourhood). To some extent, Feng-shui intersects with this knowledge and tradition (Mak \& Thomas, 2005). However, whether it is suitable for modern residential building design has not been verified. This paper employs virtual simulations for analysing new residential buildings in Lingnan (Tian, 2019).

\section{METHODS \\ SOFTWARE}

Virtual simulation is to use relative software to analyse the real environment in the computer. For wind, thermal, acoustic, and light environments, various software programs can be used. In this paper, PHOENICS, ENVI_MET, CadnaA, and Ecotect software were separately used, as Table 2 shows (Wang et al., 2016).

\begin{tabular}{ccccc}
\hline Function & Wind simulation & $\begin{array}{c}\text { Thermal } \\
\text { simulation }\end{array}$ & $\begin{array}{c}\text { Acoustic } \\
\text { simulation }\end{array}$ & Light simulation \\
\hline Software & PHOENICS & ENVI_MET & CadnaA & Ecotect \\
\hline Logo & C Cadna D D & A & &
\end{tabular}

\section{SETTINGS}

PHOENICS is the first, and the most established, commercial Computational Fluid Dynamics (CFD) software available. It can simulate scenarios involving fluid flow, heat and mass transfer, chemical reaction, and combustion (Guo et al., 2015a). The method used mainly to analyse the wind environment in this software includes four parts. The first is to establish a computational fluid dynamics model. Here, the three 'neighbourhood', 'block', and 'single courtyard' scale models were built by Sketchup then imported to PHOENICS. The second is to set the boundary conditions according to the Standard for Green Performance Calculation of Civil Buildings (MOHURD, 2018). The third is to generate computational domain size and mesh in software, and the last is to set 
the number of iterations and start counting ( $\mathrm{He}$ et al., 2019). Generally, for wind environment analysis, the conditions in summer and winter should be simulated. Figure 1 shows the summer settings.

ENVI_MET is a holistic microclimate model that was designed back in 1994. The models' calculation modules span a wide range of scientific disciplines, from fluid dynamics and thermodynamics to plant physiology and soil science. However, it is not suitable for simulating the indoor thermal environment, as other researchers mentioned (Fahmy \& Sharples, 2009; Peng \& Elwan, 2014). Here, ENVI_MET was used to analyse the residential outdoor thermal environment. The method has four steps. The first step is to create model domain settings, such as model location and model geometry. The second is to build a model (Figure 2). Then, the ENVIGuide is set, including the start date, the total simulation time, and soil conditions. The fourth step is starting the simulation and analysis of the results.

Computer-aided noise abatement (CadnaA ) is the leading software for the calculation, presentation, assessment, and prediction of environmental noise. The research used this to simulate outdoor noise. The method is divided into five steps. The first step is to build the neighbourhood model by using CAD software and then export the DXF file. The next step is to set the configuration of calculation. Then, import the DXF file to the software. The fourth step is to rebuild the neighbourhood model in CadnaA, especially considering the noise distribution (Figure 3). The last step is to calculate and export the results (Bastián-Monarca et al., 2016).

Ecotect is an environmental analysis tool that allows designers to simulate building performances such as sunlight, lighting and shadows (Sher et al., 2019). Because the whole neighbourhood faces south with the back to the north, and each single courtyard sunlight condition is similar, only the single courtyard sunlight environment was simulated by Ecotect with four steps. The first step is to build a model in the software (Figure 4). The second step is to reset the analysis grid. The third step is to set the calculation wizard (the simulation period, object overshadowing, etc.). The fourth step is to start calculation and then get the analysis results.

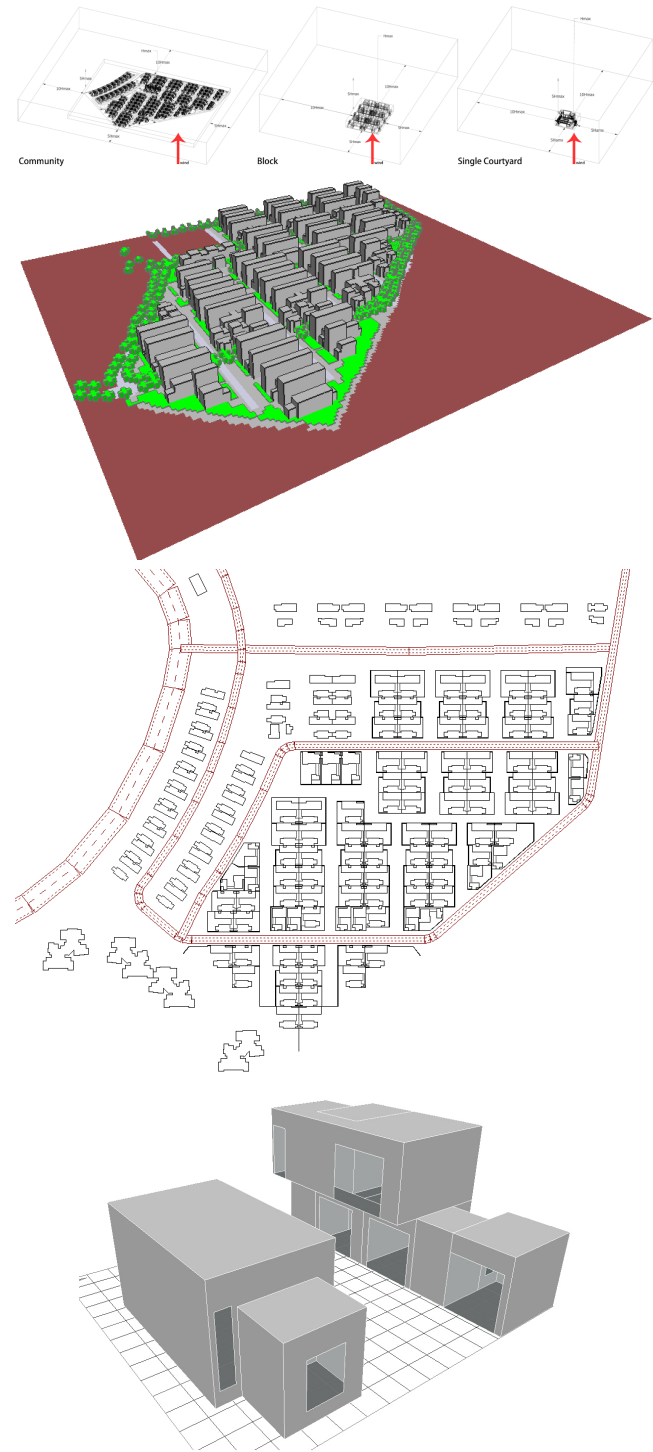

Figure 1

Simulation setting of summer.

Figure 2

Simulation model in ENVI_MET.

Figure 3

Simulation model in CadnaA.

Figure 4

Simulation model in Ecotect. 
Figure 5

Neighbourhood wind simulation result.

Figure 6

Block wind

simulation result.

Figure 7

Single courtyard wind simulation result.

\section{RESULTS}

Based on the methods of four different software used to simulate the case of new residential buildings in Lingnan according to relevant standards, the results try to find out the problems in the modern buildings from XS to XL scale contexts.

\section{WIND SIMULATION RESULTS}

For the wind simulation, the neighbourhood result showed there were calm wind zones in the summer. That is not a pleasant wind environment because it is hot during the summer in Lingnan. Wind in the summer would be better even though the simulation of the wind environment is good in the winter (Figure 5). However, the orientation of the neighbourhood can be optimised further. The block simulation result showed that there are calm wind zones in the main rooms in summer, especially in the west of the block (Figure 6-b). According to the Assessment Standard for Green Building, there should not be calm wind zones in the main activity area in summer (MOHURD, 2019). Moreover, the layout of the single courtyard causes fresh air to go through from the bathroom to the main rooms all year (Figures 6-a and d). This can also be verified in Figures 7-a and c. Nevertheless, the Standard of the Measurement and Evaluation for Efficiency of Building Ventilation shows that indoor ventilation should flow from main rooms, such as the living room and bedrooms, to functional rooms, such as the bathroom (MOHURD, 2013 (a)). So the wind environment problems should be optimised (He \& Schnabel, 2016).

\section{THERMAL SIMULATION RESULTS}

For the thermal simulation, the residential outdoor thermal environment was simulated by ENVI_MET. The result showed that the heat island index is more than $1.5^{\circ} \mathrm{C}$ from $14: 00$ to $17: 00$ in summer. According to the requirement of the Design Standard for Thermal Environment of Urban Residential Areas (MOHURD, 2013 (b)), the thermal environment is not suitable for users. That should be optimised (Table 3 ).
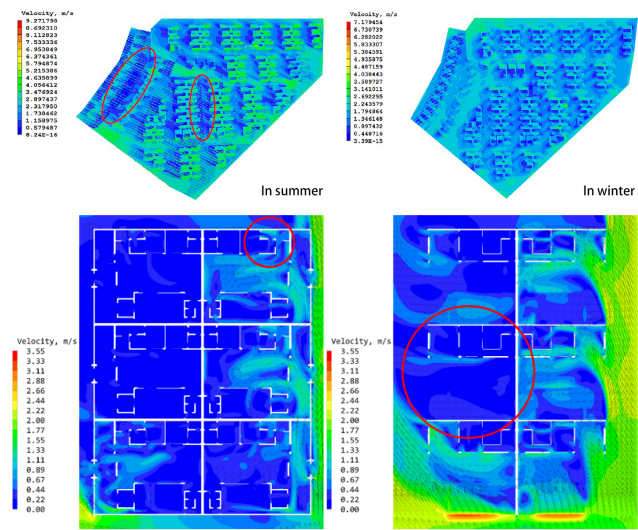

(a) First floor in summer

(b) Second floor in summer
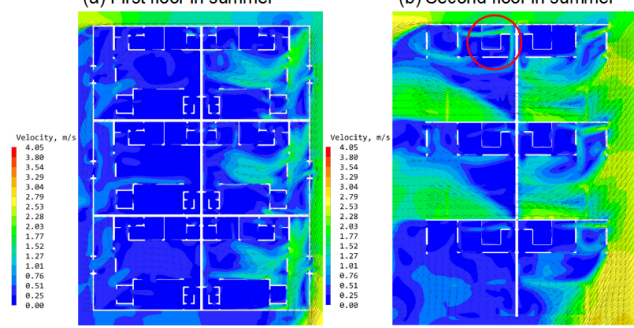

(c) First floor in winter

(d) Second floor in winter
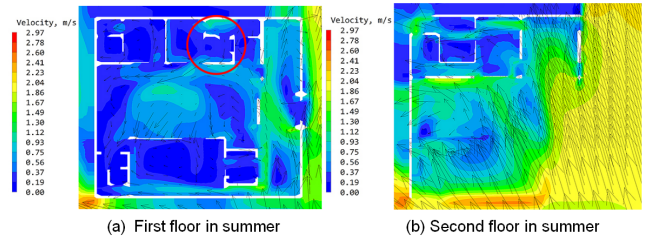

(b) Second floor in summer
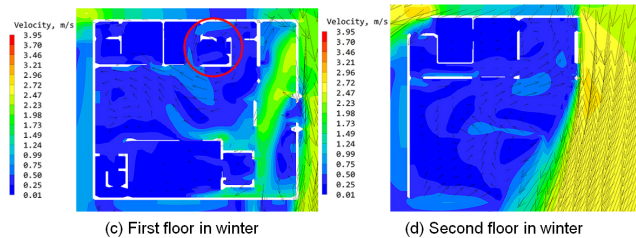

(c) First floor in winter

(d) Second floor in winter

\section{ACOUSTIC SIMULATION RESULTS}

For the acoustic environment, the outdoor noise simulation result showed noise between $21 \mathrm{~dB}$ and $55 \mathrm{~dB}$ during the daytime and between $11 \mathrm{~dB}$ and $45 \mathrm{~dB}$ dur- 
ing the night (Figure 8). They just meet the standard requirements of no more than $55 \mathrm{~dB}$ in the daytime and no more than $45 \mathrm{~dB}$ at night (AQSIQ, 2008). It can be optimised according to vernacular knowledge for a better acoustic environment.

\begin{tabular}{cccc}
\hline Time & Specified temperature $\left({ }^{\circ} \mathrm{C}\right)$ & Simulated temperature $\left({ }^{\circ} \mathrm{C}\right)$ & Heat island index $\left({ }^{\circ} \mathrm{C}\right)$ \\
\hline $9: 00$ & 29 & 28.82 & -0.18 \\
$10: 00$ & 29.7 & 29.56 & -0.14 \\
$11: 00$ & 30.4 & 30.71 & 0.31 \\
$12: 00$ & 30.9 & 31.52 & 0.62 \\
$13: 00$ & 31.1 & 32.2 & 1.1 \\
$14: 00$ & 31 & 32.66 & 1.66 \\
$15: 00$ & 30.7 & 32.53 & 1.83 \\
$16: 00$ & 30.1 & 31.99 & 1.89 \\
$17: 00$ & 29.4 & 31.34 & 1.94 \\
$18: 00$ & 28.8 & 30.21 & 1.41 \\
$19: 00$ & 28.1 & 28.95 & 0.85 \\
\hline Average value & 29.93 & 30.95 & 1.02 \\
\hline
\end{tabular}

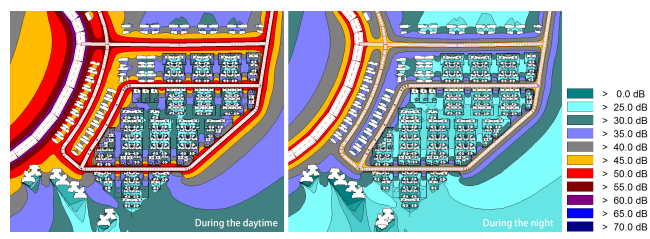

\section{LIGHT SIMULATION RESULTS}

For the light environment, the single courtyard sunlight environment was simulated. The average value of the daylight factor is $9.44 \%$ on the first floor and $6.09 \%$ on the second floor. These values meet the requirement of no less than $2 \%$ daylight factor in the Standard for Daylingting Design of Buildings (MOHURD, 2013 (c)). However, near the window, the daylight factor is higher than $10 \%$. It could cause a glaring problem, which can be optimised (Figure 9).
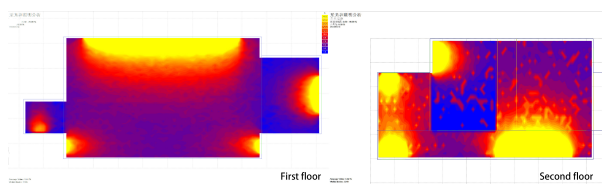

\section{DISCUSSION}

The wind, thermal, acoustic, and light environments of new residential buildings in Lingnan were separately simulated by virtual simulation methods.
Three distinct questions arose during the simulation process: (1) Is the vernacular knowledge useful? (2) How can we use vernacular knowledge to solve these problems? (3) Can we transfer the traditional knowledge into a current context, from XS to XL? These all need to be discussed.

\section{OPTIMISED WIND SIMULATION}

For the wind environment, the orientation of the neighbourhood should influence the direction of the wind. Therefore, the optimised design, according to vernacular knowledge in Lingnan, suggests that the building location should gradually rise with the site from the south to the north. It will increase ventilation in the summer and decrease it in the winter. On the block level, the clam wind zones mainly exist on the west side, so the blocks need to be detached from each other in the north-south orientation. The optimised block design is just like the comb layout based on vernacular knowledge in Lingnan (Table 4-A). Furthermore, the cold lanes are also generated because of the use of the comb layout (Table 4-B) (Guo et al., 2015 (b)). PHOENICS was used to simulate the optimised design of the neighbourhood and block (Figure $10 \& 11$ ). For the single courtyard, the functional rooms, such as the bathroom, were put in the downwind position. That will help to solve the existing air pollution problem (Figure 12). The courtyard is still used for a better wind environment (Table 4-C). As the previous research verified, the courtyard is useful, whether in summer or winter (Xu et al., 2018). Finally, all the problems were solved. To some extent, these prove that vernacular knowledge can be used for modern buildings from XS to XL.

\section{OPTIMISED THERMAL SIMULATION}

For the thermal simulation, vernacular knowledge in Lingnan is used in general to increase greenery, water areas, and hollow fences. Based on the simulation of ENVI_MET, the heat island phenomenon was a problem. Therefore, the measures of increasing greenery and water areas were simulated separately. The comparison of the optimised simulation
Table 3

Thermal simulation result.

Figure 8

Acoustic simulation result.

Figure 9 Light simulation result. 
Table 4

Optimised design

by vernacular wisdom.

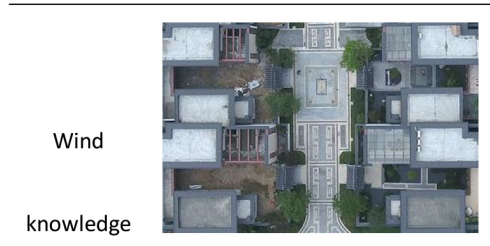

A: Comb layout

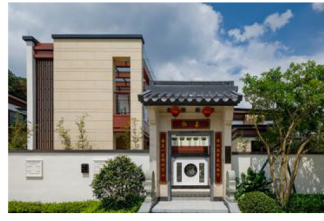

B: Cold lanes

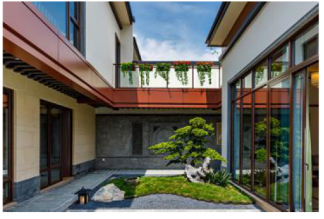

C: Courtyard

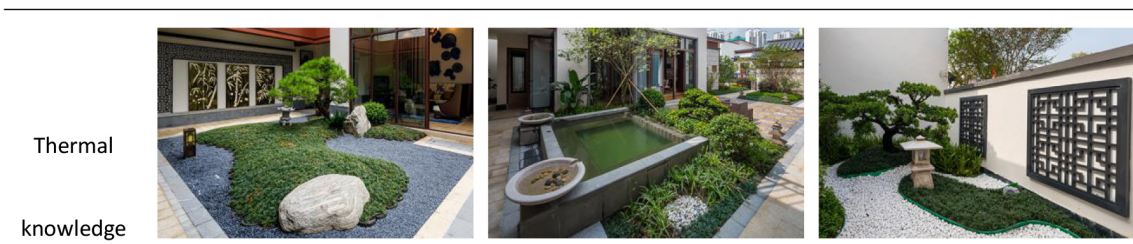

D: Greenery

E: Water areas

F: Hollow fences

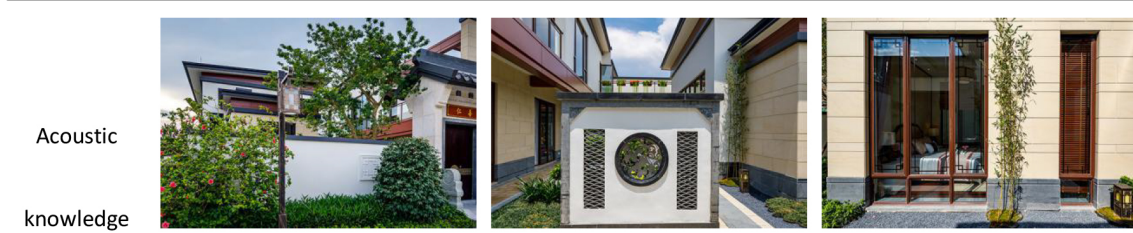

G: High-rise plants

$\mathrm{H}$ : Soundproof walls

I: Tight building envelopes

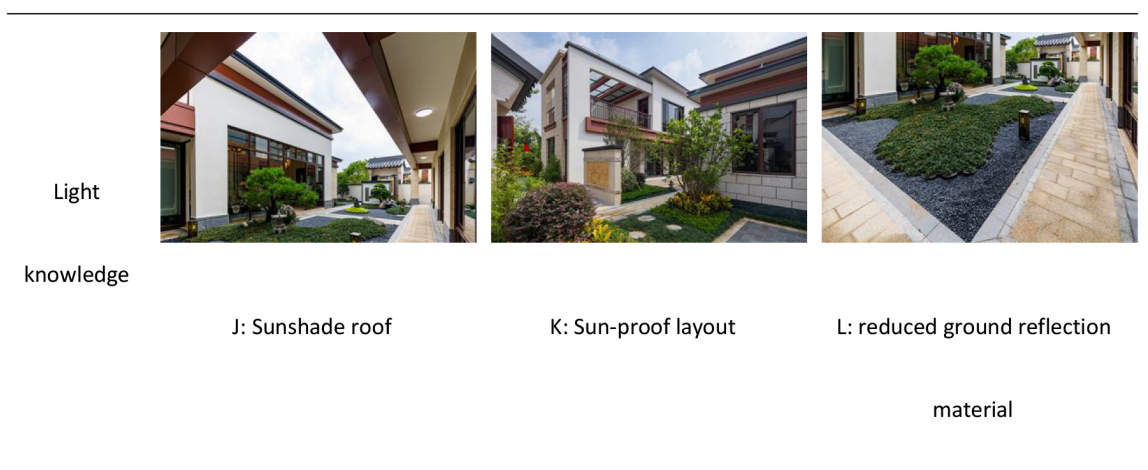


with the original at 16:00 is shown in Figure 13. It shows that the optimised design based on vernacular knowledge solved the heat island problem (Table 4-D \& E). For the hollow fence, the real new residential buildings also used it to improve the thermal environment (Table 4-F). This indicates that the vernacular knowledge of the thermal environment can still be used today. The rationality of vernacular knowledge was also verified by other researchers (Du et al., 2016; Nguyen et al., 2019).
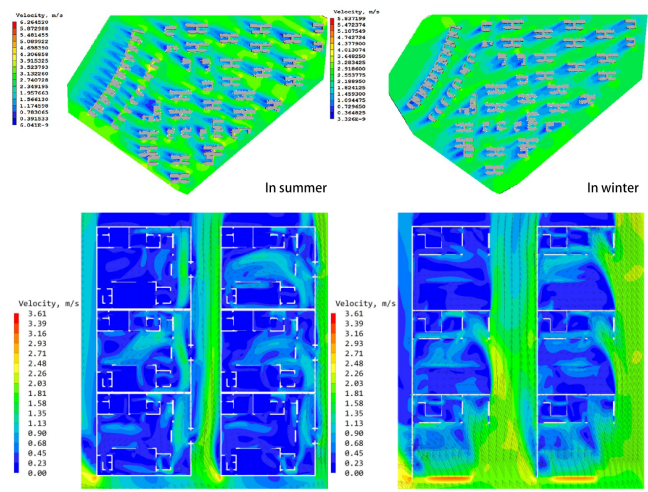

(a) First floor in summer

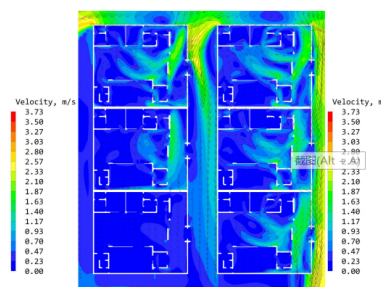

(b) Second floor in summer

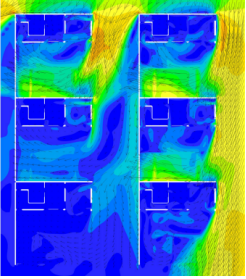

(c) First floor in winte

d) Second floor in winter
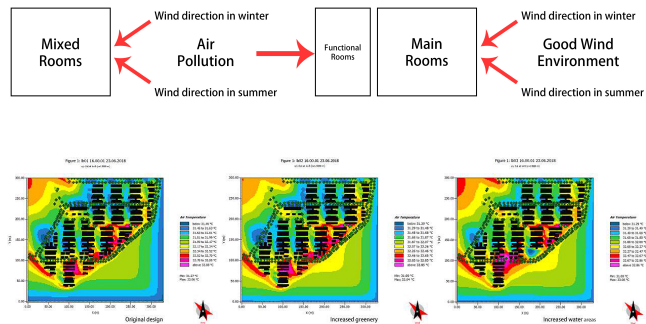

\section{OPTIMISED ACOUSTIC SIMULATION}

For the acoustic environment, the CadnaA simulation showed that results meet the requirements of the standard. However, for vernacular knowledge, the measures of high-rise plants, soundproof walls, and tight building envelopes were typically used. Tall-growing plants not only help to address issues caused by the heat-island effect but are also useful for reducing the spread of noise. Often structures such as soundproof walls are erected to reduce noise. In vernacular buildings, a more sensible approach is employed. By placing a unique wall in the courtyard opposite the entry reduces the noise that comes from the entry door. Besides, the solid building envelopes used in vernacular buildings provide an improved indoor acoustic environment. These are samples of how vernacular wisdom can aid new residential buildings to reduce environment noise (Table 4-G \& H \& I) (Vukmirovic et al., 2019).

\section{OPTIMISED LIGHT SIMULATION}

For the light environment, to prevent glare in the single courtyard building a sunshade roof is constructed, while at the same time, material that is less reflective is used in the vernacular building practice (Table 4-J \& K \& L). These sunshade roofs are being used all over Lingnan due to the high solar elevation angle. Building layouts are placed such that westfacing facades or windows avoid intense solar radiation exposure. Here, the sunshade roof situation simulated in the Ecotect. The optimised daylight factor is $4.97 \%$. It is better than before, not only meeting the requirement of the standard but also avoiding the glaring problem (Figure 14).

\section{DISCUSSION SUMMARY}

Finally, the optimised design has been constructed and tested in real buildings (Table 4). They verify that it is beneficial to employ Lingnan's vernacular knowledge in new residential building developments to achieve an overall better environment from XS to $\mathrm{XL}$ scales. The traditional vernacular knowledge includes the more known aspects of Feng-shui. The
Figure 10

Optimised neighbourhood simulation.

Figure 11 Optimised block simulation.

Figure 12

Optimised single courtyard design.

Figure 13

Comparison of thermal simulation. 
Figure 14 Comparison of light simulation. previous research by Li et al. (Li et al., 2020) has confirmed that Lingnan's vernacular knowledge is still being used today. In their research, virtual building simulations have been employed to validate the recommendations given in vernacular wisdom. Architects and designers of new residential buildings in Lingnan are referring to vernacular building traditions to achieve better building and living conditions. The presented study has confirmed that vernacular knowledge that is part of a larger body of traditions, wisdom or philosophies has valid points to generate architectures that satisfy not only cultural needs but also these of current building regulations and performances that are defined via means of computational architectural and building science.

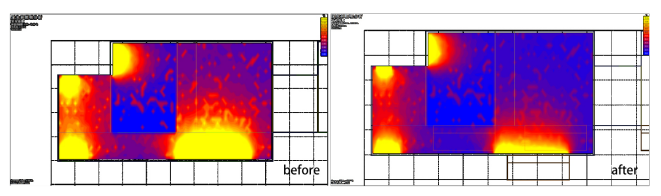

\section{CONCLUSIONS}

The virtual simulations based on PHOENICS, ENVI_MET, CadnaA, and Ecotect software are the methods to simulate and analyse the case of new residential buildings in Lingnan. The results of wind, thermal, acoustic, and light environment simulations showed the new building design defects separately. For the wind environment, the neighbourhood orientation should be optimised; moreover, the blocks should be detached. The single courtyard should put the functional rooms in the downwind position. For the thermal environment, there exists a heat island problem. For the acoustic environment, the results meet the requirements of the standard, but this can also be optimised. Finally, for the light environment, the glare problem exists.

By combining this with the vernacular knowledge, these problems are solved. The built-up optimised design used a comb layout to solve the calm wind zones, generating cold lanes and courtyards for a better wind environment. It not only increased the greenery and water areas to solve the heat island problem, but it also used hollow fences for a better thermal environment. For better acoustics, the optimised design used high-rise plants, soundproof walls, and tight building envelopes. Furthermore, the buildings used sunshade roofs, sun-proof layouts, and reduced ground-reflecting material to solve the glare problem.

Research through virtual simulation verified that vernacular knowledge can still be used for new residential buildings from XS to XL in Lingnan. To some extent, the research has also confirmed that the wisdom of Feng-shui contributes positively to how we design and construct buildings and neighbourhoods nowadays.

\section{ACKNOWLEDGMENT}

This research was supported by the National Key R\&D Program of China (Grant No. 2017YFC0702505); General Program of National Natural Science Foundation of China (No. 51678239); Science and Technology Program of Guangzhou, China (No. 201804020017).

\section{REFERENCES}

Bastián-Monarca, NA, Suárez, E and Arenas, JP 2016, 'Assessment of Methods for Simplified Traffic Noise Mapping of Small Cities: Casework of the City of Valdivia, Chile', Science of The Total Environment, 550, pp. 439-448

Ministry of Housing and Urban-Rural Development of the People's Republic of China, MOHURD 1993, Standard of Climatic Regionalization for Architecture, China Planning Press

General Administration of Quality Supervision, Inspection and Quarantine of the People's Republic of China, AQSIQ 2008, Environmental Quality Standard for Noise, China Environmental Science Press

Ministry of Housing and Urban-Rural Development of the People's Republic of China, MOHURD 2013 (a), The Standard of the Measurement and Evaluation for Efficiency of Building Ventilation, China Architecture \& Building Press

Ministry of Housing and Urban-Rural Development of the People's Republic of China, MOHURD 2013 (b), Design Standard for Thermal Environment of Urban Residential Areas, China Architecture \& Building 
Press

Ministry of Housing and Urban-Rural Development of the People's Republic of China, MOHURD 2013 (c) Standard for Daylingting Design of Buildings, China Architecture \& Building Press

Ministry of Housing and Urban-Rural Development of the People's Republic of China, MOHURD 2018, Standard for Green Performance Calculation of Civil Buildings, China Architecture \& Building Press

Ministry of Housing and Urban-Rural Development of the People's Republic of China, MOHURD 2019, Assessment Standard for Green Building, China Architecture \& Building Press

Du, XY, Bokel, R and Dobbelsteen, AVD 2016, 'Architectural Spatial Design Strategies for Summer Microclimate Control in Buildings: A Comparative Case Study of Chinese Vernacular and Modern Houses', Journal of Asian Architecture and Building Engineering, 15, pp. 327-334

Fahmy, M and Sharples, S 2009, 'On the Development of an Urban Passive Thermal Comfort System in Cairo, Egypt', Building and Environment, 44, pp. 1907-1916

Gao, YF and Cheng, JJ 2011 'Experiments on Outdoor Thermal Comfort of Traditional Comb-layout Village in Lingnan China', Procedia Engineering

Guo, WH, Liu, X and Yuan, X 2015 (a) 'Study on Natural Ventilation Design Optimization Based on CFD Simulation for Green Buildings', Procedia Engineering, pp. 573-581

Guo, WH, Liu, X and Yuan, X 2015 (b) 'A Case Study on Optimization of Building Design Based on CFD Simulation Technology of Wind Environment', Procedia Engineering, pp. 225-231

He, Y and Schnabel, MA 2016 'A CFD Analysis of Walleffect Building Groups in a Curved Layout: A Study in Sha Tin, Hong Kong', Proceedings of the 11th ISAIA, pp. 1771-1776

He, Y, Schnabel, MA and Mei, Y 2019, 'A novel methodology for architectural wind environment study by integrating CFD simulation, multiple parametric tools and evaluation criteria', Building Simulation, 13(3), pp. 609-625

Ji, WD, Li, HB, Zhang, FF and Qin, H 2018, 'Low energy technology for chinese traditional dwellings', Building Energy Efficiency, 46, pp. 17-21

Li, B, Guo, WH, Schnabel, MA and Moleta, T 2020 'FengShui and Computational Fluid Dynamics (CFD): Analyzing Natural Ventilation and Human Comfort', Proceedings of CAADRIA 2020, Bangkok, 1, 731-740

Lin, L, Lu, Q and Zhang, KN 2019, 'A Study on Ecological Wisdom and Simulation Analysis of the Spatial Form of Traditional Settlements in the Lingnan Area', New Architecture, 1, pp. 135-139

Liu, K, Wang, JG and Tang, P 2018, 'Sprawling Urban Form and Expanding Living Space: A Study on the Relationship of Residential Space Development and Urban Built-up Area Expansion in Nanjing, China', Journal of Asian Architecture and Building Engineering, 14, pp. 387-394

Mak, MY and Thomas, Ng S 2005, 'The Art and Science of Feng-Shui-A Study on Architects' Perception', Building and Environment, 40, pp. 427-434

Nguyen, AT, Truong, NSH, Rockwood, D and Tran Le, AD 2019, 'Studies on Sustainable Features of Vernacular Architecture in Different Regions across the World: A Comprehensive Synthesis and Evaluation', Frontiers of Architectural Research, 8, pp. 535-548

Peng, CZ and Elwan, A 2014, 'An Outdoor-indoor Coupled Simulation Framework for Climate Change-Conscious Urban Neighborhood Design', Simulation-Transactions of the Society for Modeling and Simulation International, 90, pp. 874-891

Sher, F, Kawai, A, Güleç, F and Sadiq, H 2019, 'Sustainable Energy Saving Alternatives in Small Buildings', Sustainable Energy Technologies and Assessments, 32, pp. $92-99$

Tian, Y 2019 'A Simulation Study on the ClimateAdaptive Design of Jiangmen Binjiang Sports Center', Journal of Physics: Conference Series

Vukmirovic, M, Gavrilovic, S and Stojanovic, D 2019, 'The Improvement of the Comfort of Public Spaces as a Local Initiative in Coping with Climate Change', Sustainability, 11, p. 20

Wang, SS, Shi, F, Zhang, BB and Zheng, JH 2016, 'The Passive Design Strategies and Energy Performance of a Zero-energy Solar House: Sunny Inside in Solar Decathlon China 2013', Journal of Asian Architecture and Building Engineering, 15, pp. 543-548

$\mathrm{Xu}, \mathrm{XD}$, Luo, FL, Wang, W, Hong, TZ and Fu, XZ 2018, 'Performance-Based Evaluation of Courtyard Design in China's Cold-Winter Hot-Summer Climate Regions', Sustainability, 10, pp. 1-19

Yang, SC and Zhou, Q 2015, 'The Scientific Analysis of Lingnan Architectural Features in Green Buildings', South Architecture, 2, pp. 28-31

Zeng, ZW, Li, L and Pang, Y 2017, 'Analysis on Climate Adaptability of Traditional Villages in Lingnan, China-World Cultural Heritage Site of Majianglong Villages as Example', Procedia Engineering, 205, pp. 2011-2018 